\title{
American Pediatric Society 2009 Presidential Address- The Complexity of Pediatric Education in the 21st Century: What Can We Do?
}

\author{
GEORGE LISTER \\ Department of Pediatrics, University of Texas Southwestern Medical Center Dallas, Dallas, Texas 75390
}

$I^{a}$ chose this topic because many of us are frustrated by events affecting medical education that seem to be out of our control and have the risk of leaving us apathetic and our progeny aimless. I will focus specifically on graduate medical education (GME) because it is closest to home for most of us and the concepts readily translate to other realms. I hope to identify some of the potentially opposing internal and external forces that have imposed strain on the educational experience. These forces, which have developed naturally or with our assistance and good intent, are pervasive and insidious and often threaten the education they may be intended to protect or promote. I offer my analysis of how we arrived at this point and some thoughts for ways to regain our enthusiasm and bearings.

The culture of medicine is changing dramatically in front of us, and it is not so easy to stop the world for us to get off. We remain bewildered by how far ahead we are in understanding fundamental features of biology; how far behind we are in delivering the knowledge to the bedside in a manner that improves care and satisfaction; and how much time we spend in medicine doing less of what we thought we were educated to do. It is no mystery that there will be further reduction in the amount of time that residents spend in direct patient care during their formative years of medical training with the decrease in work hours and increase in layers of regulations and red tape. If Malcolm Gladwell (1) is correct, one predictable consequence is that it will take longer to reach 10,000 h, which he cites as the practice time "required to achieve the level of mastery associated with being a world-class expert-in anything." We can bemoan the loss of the milieu and experiences that made our own training exciting (perhaps glorified by our filtered memory) or we can find the means to reinfuse vigor and creativity into our progeny through their education. Accordingly, I hope to stimulate you to consider: how we can keep our students engaged, challenged, and excited; keep ourselves equally engaged, challenged, and excited; and keep the educational process vibrant and stimulating. Frankly, if we

Received March 10, 2011; accepted March 11, 2011.

Correspondence: George Lister, M.D., Department of Pediatrics, University of Texas Southwestern Medical Center Dallas, 5323 Harry Hines Blvd, Dallas, TX 75390; e-mail: george.lister@utsouthwestern.edu

Presented at the 2009 Annual Meeting of the Pediatric Academic Societies, Baltimore, Maryland. cannot address this problem, who can? We do not have the luxury to reassign the responsibility to those without the authority.

Some background might be useful here to see how postgraduate education has evolved. The Flexner Report, commissioned by the Carnegie Foundation and published in 1910, was the first comprehensive evaluation of formal medical education; it was written after the author visited all 155 US medical schools in 18 mo and examined five principal areas of education (2). It is worth reflecting for a moment on some of the prescient comments attributed to Flexner (3): all learning is selflearning. Teachers might stimulate or inspire, but "students learn more than they are taught." The medical school couldn't begin to produce fully trained doctors. Medical school could only introduce students to the methods of scientific medicine and thus make them "active learners." These thoughts are equally insightful and relevant today as we contemplate what we can actually accomplish as teachers and how we might educate students to confront a complex and changing world with the explosion of medical knowledge. They also reinforce my belief that there is no means or reason to condense all the "needed" content into curriculum, but we might stimulate life-long learning and help students develop the tools and enthusiasm for this.

The students of the Flexner era became the residents and interns in the halcyon days in the 1920s and 1930s when they earned their moniker "house officer" because they lived in the hospital, worked for the privilege of the teaching they received, and learned at the bedside from endless experience. Over the subsequent years, schedules were developed to add civility to the life of a house officer-that is $36 \mathrm{~h}$ on/12 h off-and then salaries were provided to recognize need for support of self and family.

In 1966, the Millis Report (4) identified serious problems in GME, particularly the fractionation of education with many free-standing residency programs that had no link to medical schools. This provided seed for the concept of a single gov-

\footnotetext{
Abbreviations: ACGME, Accreditation Council for Graduate Medical Education; CME, Continuing Medical Education; ECMO, extracorporeal membrane oxygenation; GME, graduate medical education; ICU, intensive care unit
} 
Table 1. Residency requirements: Evolution by prescription

\begin{tabular}{|c|c|c|c|c|}
\hline Area/year & 1978 & 1985 & 1997 & Present \\
\hline Ambulatory & $6 \mathrm{mo}$ & $6 \mathrm{mo}$ & $1 / 2$ training & $1 / 2$ training \\
\hline Continuity & & $1 / w k$ or $/ 2$ wk for $3 y$ & $1 / 2 \mathrm{~d} / \mathrm{wk}$ for $3 \mathrm{y}$ & 36 half days/y for $3 y$ \\
\hline Acute/emergency care & Should be $3 \mathrm{mo}$ & Must be 3 mo & Must be 4 mo & $4 \mathrm{mo}$ \\
\hline Adolescent & & Need experience & $1 \mathrm{mo}$ & $1 \mathrm{mo}$ \\
\hline Development/psychiatry & & Structured experience & $1 \mathrm{mo}$ & $1 \mathrm{mo}$ \\
\hline Newborn nursery & & Need experience & $1 \mathrm{mo}$ & $1 \mathrm{mo}$ \\
\hline Neonatal ICU & & $4-6 \mathrm{mo}$ & $3-5 \mathrm{mo}$ & $3-4 \mathrm{mo}$ \\
\hline Pediatric ICU & & & $1 \mathrm{mo}$ & $2 \mathrm{mo}$ \\
\hline
\end{tabular}

erning body to oversee graduate education, initially the Liaison Committee for GME and then the Accreditation Council for Graduate Medical Education (ACGME) and the concept of sponsorship by a medical school. The report of a Task Force on Pediatric Education followed in 1978 (5). It concluded that the minimum duration of residency should be 36 mo. It stressed the need for increased educational experience in a variety of areas including biosocial and developmental pediatrics; adolescent medicine; clinical pharmacology and toxicology; community pediatrics; handicapping conditions and chronic illness; medical ethics; musculoskeletal, skin, and dental disorders; nutrition; and electives in areas of special interest. Thus, this set the tone for increased specification of clinical rotations. The next major evaluation, The Future of Pediatric Education II, published in 2000 (6), recommended the enhancement of the science of pediatric medical education, flexible 3-y residency to train pediatricians for varied professional roles, ongoing evaluation and revision of core competencies, and incorporation of anticipated needs for future practice.

Distribution of educational activities. Although these thoughtful documents helped shape our current residency, one of the consequences has been evolution by prescription. Deeply committed individuals wrestled with fundamental educational issues and created requirements intended to improve the design of the training experience. However, this has also caused progressively increased specificity and reduced flexibility in pediatric residency education (Table 1) shown simply by the fact that more boxes are filled with successive changes in requirements. This specification may be one of the interesting forces that has both a compelling rationale and a substantial untoward effect.

The creation of the pediatric residency has certainly been molded by understandable intentions to respond to such factors as the perceived "need" to sample a variety of clinical settings and experiences and to distribute time in closer proportion to future professional activities. On the other hand, it has not necessarily been shaped by the opportunity for independent growth, development, responsibility, cultivation of curiosity, and development of critical thinking that helps the student mature. My concerns are embodied in the homunculus portraying the 21st century resident. Has education been molded by evolution or by intelligent design? (Fig. 1).

To illustrate, I shall pick a polar example and one that is likely to be controversial, the experience in critical care. As intensive care units (ICUs) were developed, the time residents spent there progressively increased because of growing ser-

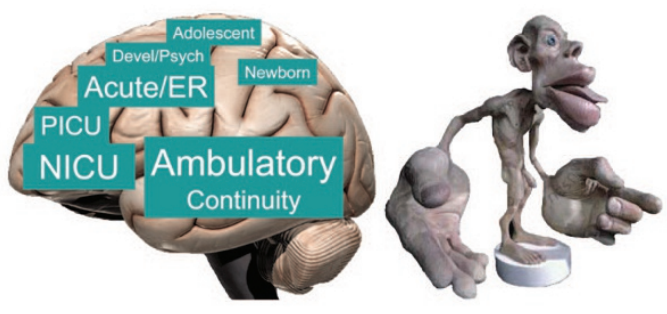

Figure 1. Pediatric resident: molded by evolution or intelligent design?

vice needs, whereas in recent years, the time has been specifically reduced because it is thought to be less relevant to subsequent practice of most residents. Perhaps neither rationale is appropriate. When appropriately guided, the experience could provide an opportunity to recognize the unstable child and understand why; become facile with physical examination (even repetitive examinations - a rarity these days) that signifies the changing physiologic state of the child; follow the evolution of an illness continuously rather than in snippets; and derive rationale, not a formula for management. It can permit acquisition of tools that offer a foundation for critical thinking. It can also be an invaluable opportunity to work with families during a time of crisis or as they face the death of their child. There is also a concentration of human resources that provide multiple points of interaction and critique for the resident. The education in the ICU should not be designed to teach residents how to manage patients on extracorporeal membrane oxygenation (ECMO) or other highly specialized equipment, to expect them to memorize needless algorithms or protocols that will be soon be discarded, or to groom intensive care physicians. The ICU does not resemble future practice site that is primarily ambulatory in nature, but maybe the environment offers a better chance than an outpatient setting to develop and reinforce the fundamental skills and knowledge needed to distinguish the healthy from the ill child and understand why the child is ill.

This point is amplified by the evolving nature of our patients who have progressively more complex and chronic illnesses. The trend is highlighted in a article by Paul Wise (7) in which he states that "among all medical admissions for children younger than age 17, approximately a quarter were associated with chronic diagnosis in 1962; by 2000 the figure had more than doubled to approximately 55\%." A consequence of this is the need for a multidisciplinary group and, perhaps, general physicians who are skilled and comfortable with the care of children who have complex diseases to lead this group. 
Perfunctory evaluations. Another factor influencing the residency has been the identification of core competencies coupled with the constant series of evaluations to assess the progress of the learner on a monthly basis. The qualities inherent in the competencies are virtuous and there is a need for reinforcement if we are to cajole and guide our residents. However, the evolving means for evaluations-pass/fail, " $\mathrm{A}$ " through "F," a Likert scale, or the contemporary $360^{\circ}$-are not worthwhile without having these mapped to tangible ideas. Every student who has been passed through high school, college, and medical school has been primed to receive an " $\mathrm{A}$ " and is indignant with anything less than excellent-an expectation reinforced by loving parents and less than critical teachers who are grateful to have an achiever in the classroom. Hence, the current assessments are a means to have an appearance of evaluation, but do not shape behavior we wish to extol. Furthermore, the current description of competencies provides platitudes that not one would deny: Residents must demonstrate a commitment to carrying out professional responsibilities, adherence to ethical principles, and sensitivity to a diverse patient population. Residents are expected to demonstrate: compassion, integrity, and respect for others; responsiveness to the patient needs that supersedes self-interest; respect for patient privacy and autonomy; accountability to patients, society, and the profession. Who would ever admit to contrary behavior? Any assertion that a resident does not adhere to these virtues becomes loaded with moral rather than educational overtones and does not permit guidance.

Increasing regulation, decreasing responsibility. Although individuals may respond to problems in a manner that depends on personality, creativity, and circumstances, societies often respond to the problems by either ignoring or regulating them. Thus, a major force that had profound influence over residency training arose in the 1960s. The Federal Government created Medicaid and Medicare in 1965. Shortly thereafter, physicians devised ways to game the system and created an array of types of billing fraud that included services not provided; misrepresentation of diagnoses; unnecessary treatments; and kickbacks. The result of this deceit was the need for detailed documentation by the supervising physician to permit payment by the government for actual services, a requirement also adopted by insurance companies. Physicians who were supervising others then developed such illuminating documentation as "agree with above," "examined and agree," or perhaps even "agree with below." What was the consequence? As the documentation by the Attending Physician has become more detailed and presence more prescribed, residents have taken progressively less responsibility and have become marginalized in the process. The writing of progress notes is often emblematic of this whereby information can be merely copied and pasted from other notes (made quite easy by the advent of the electronic record), and the text only describes the events rather than explaining them.

The next major force was galvanized by the case of Libby Zion, an 18-y-old woman who died $6 \mathrm{~h}$ after admission to the New York Hospital. Her father, a writer for the New York Times, claimed his daughter had received inadequate care from the overworked, undersupervised house officers. This case prompted a Grand Jury Investigation and subsequently a panel of physicians appointed by the New York State Health Commissioner to investigate emergency care and training of physicians. The latter resulted in the New York State Department of Health Code, Section 405, also known as the Libby Zion law, which restricted resident physicians' work hours and served as a basis for current limitations. There are many disputed issues in her care but a couple of things were clear. The only physicians who saw and treated her that night were two junior residents; the senior physician was at home and involved only by phone; one of the residents had been on about $18 \mathrm{~h}$ and the other $19 \mathrm{~h}$. The recommendations from the investigation, and in specific response to the poor supervision and exhaustion, were additional, albeit well earned and justified regulations. However, the potential untoward consequences include reduced responsibility for the learner, reduced time with patients, and reduced ownership. The staccato relationship with patients contributes to handoffs of information reminiscent of our $4 \times 100 \mathrm{~m} 2008$ Olympic Relay Teams, i.e. dropped batons by world class runners.

Massive increase in medical information. Another force that has influenced the educational process is the rapidly expanding mass of medical knowledge. The amount of information is indigestible even by the most voracious reader; it can be so overwhelming that it promotes development of condensed content and it invites short cuts to learning-as if these approaches actually improve comprehension. However, we as educators often reinforce the need to digest more content, by insisting on more didactic activities and assessment of learning almost exclusive by detailed standardized tests. Education must incorporate means to develop nimbleness in thinking, not just developing an encyclopedic recall. This is conveyed best by BF Skinner, the psychologist, who said "Education is what survives when what has been learned has been forgotten."

Education is a wicked problem. Thus, pediatric training has been shaped by the forces that lead me, among others, to characterize this education as a wicked problem (8). This concept of a wicked problem was originally proposed by in a treatise for social planning (9). Rittel expounded on the nature of ill-defined design and planning problems, which he termed wicked, because they are messy, circular, aggressive in contrast with tame problems of mathematics, chess, or puzzle solving. They have incomplete, contradictory, and changing requirements; while attempting to solve a wicked problem, the solution reveals or creates another, even more complex problem; and solutions are difficult to recognize because of complex interdependencies. Let me offer some examples:

Incomplete, contradictory, and changing requirements

- We want to cultivate attentive, committed clinicians, but we extract them from bedside for formal didactic education and often interrupt their presence with a patient. Even if someone else "covers" the clinical duties for the resident, the responsibility, experience, and commitment essential for learning to care for a patient have been relegated to a lower priority and are necessarily tempered.

- If we wish to nurture responsible and professional physicians who demonstrate dedication to their patients, how 
does an imposed time limit on patient engagement serve that goal? Would professional behavior not be better promoted by having physicians learn to struggle with competing priorities and develop their own strategies to do so?

While attempting to solve a wicked problem, the solution reveals or creates another, even more complex problem.

- The need to work as team is important but can cause multiple physicians to have only part of the responsibility, so that no one has ownership.

- The continuity clinic, which was created to promote continuity in one setting, simultaneously creates discontinuity in another, the site where the resident has his/her primary responsibility.

Solutions are difficult to recognize because of complex interdependencies.

- What is more important to determine as the benefit of a change in an educational process - the mastery of content or the adroitness and creativity of the learner to use effectively an ever expanding and changing content? If the focus is content, it is relatively simple to assess, but what is taught initially may become obsolete all too soon. If the focus is capability to derive new ideas and adapt to new challenges, that skill may be very difficult to assess in the short term, and many interposed factors can be responsible for nurturing the nimble learner over the long term.

- Should the curriculum be designed to give residents maximal opportunity to sample career options or maximal opportunity to focus on what is of primary interest? The former might optimize the chance that an undifferentiated pediatrician can find an area that is exciting, but much of the training could be viewed as superfluous and timeconsuming for the individual whose goals are determined. If a program is designed so that residents have maximal opportunity for flexibility in their education, how will patients receive care when the residents are not predictably available? And how will residents maximize their opportunity to learn if they do not have responsibility for patient care?

Suggestions. To summarize here, I would offer that the education of our residents is plagued and distorted by complex interdependencies that are inherent in wicked problems and arise from evolving forces, which have contradictory or confounding effects (Fig. 2). There are no simple solutions for complex problems and I make no pretense that my suggestions are all my original ideas nor a panacea, but I hope these provoke thought, discussion, action, and some bold steps. As leaders, we cannot ignore the problems and hope they abate. We must think hard about the type of physicians we are educating and how we accomplish that task. Physicians must be trained both to be experts today, and equally important to be expert at becoming experts. In a rapidly changing world where healthcare can be vastly different in $5 \mathrm{y}$, we want to make sure we are not making experts in archaic practice. Now is the time to take mastery over some of these forces that have evolved for good reasons but have simultaneously enslaved

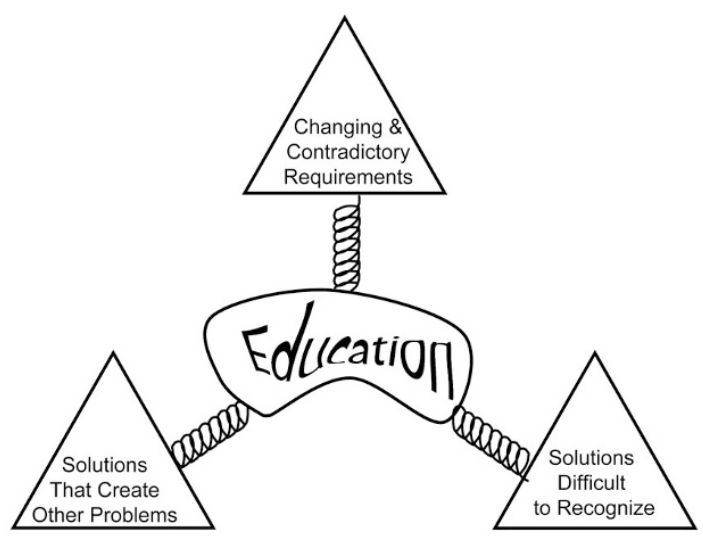

Figure 2. Complex interdependencies that distort education of residents.

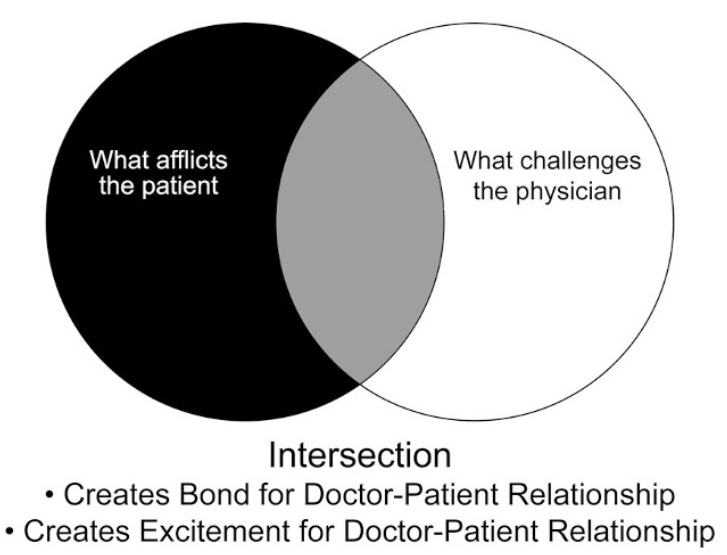

Figure 3. Basis for doctor-patient relationship.

the educational process. Even if we make mistakes, we must step out, take initiative, and start learning from the errors. And, who else but we leaders in academic pediatrics have the responsibility, the authority, and the opportunity to address the fundamental problems described here.

- Model excitement in a setting where the patient and the senior physician are in the same room. This is the most direct means to impart our own zest for learning. Discussing patients with a group of physicians, students, and nurses on rounds in the back room of an inpatient ward, out of sight from the patients, does not convey that enthusiasm and never will. As Yeats eloquently stated and Flexner must have recognized, "Education is not the filling of the pail, but the lighting of a fire." Where does the fire arise, from the intersection of what afflicts the patient and what challenges the physician (Fig. 3). The doctor-patient relationship creates excitement; it also, of course, creates a bond that provides long-term reinforcement to sustain the mutual interest to improve the health of the patient. Our residents need to see this relationship-and see this often.

- Increase Responsibility for Residents. Learning is prompted and stimulated by responsibility, and it is imperative that we find a means to reinsert this into the experience for the residents while being mindful of the need to have exemplary patient care. It will not be simple because the understandable regulations that require supervising physicians to have 
a presence and acknowledge their responsibility can eliminate the role of the residents, but I submit that it is possible. Here are some examples how:

a. Have residents function as comprehensive inpatient team for an extended period of time (perhaps 6-12 mo or more) in which they share all responsibilities. They would function as a sustained group practice and rely on another for all features of patient coverage. Rather than rotating from service to service, they would be accountable for patient outcomes and performance with respect to defined metrics, and their outcomes would be compared with other practices. An alternative would be to develop a comprehensive chronic care management practice (run by general pediatricians, not subspecialists) and residents for both inpatient and outpatient care. The residents would be fully integrated into the practice and would see patients nights and weekends, and would make home visits when needed. Every academic medical center has a group of potentially disaffected patients with complex health care needs and no primary care provider. This could be a valuable experience for residents, a vital service for patients, and a genuine opportunity to understand what families of these children face. It should extend throughout residency.

b. Have residents take telephone calls at home from their peers to address questions in management that were not clear or not mentioned during "sign out." This might prompt residents to learn how to be selective and transmit the most important and relevant information. Needed information for patient care that was not transmitted will become rapidly apparent, and extraneous information that can be derived from a chart will be reduced or eliminated. Such an exchange among peers will shape future education and subsequent interactions; the resident at home is not likely to enjoy being called for something he/she should have mentioned. This has the potential to improve the quality of progress notes as well as the nature and quality of "handoffs." The merits of this could even be tested: does this approach improve the efficiency of handoffs by assessing the number of unresolved questions/unit time of sign out, by measuring the frequency of medical error related to sign out, and by assessing professional satisfaction? It might also identify gaps in knowledge.

- Change the Approach to Evaluations of Professional Behavior. Stop reliance on grades or Likert scale data and provide examples of what we expect for development. These developmental signposts or milestones will help individuals understand the maturation without having the shame of a " $\mathrm{C}$ " on their record (Fig. 4). It is a valuable exercise to have the learner assess where he/she is on this continuum and even cite examples. This assessment offers the opportunity to determine whether the perception of the student is concordant with that of the teacher. If so, there is no negotiation over the evaluation, only discussion over what are subsequent steps or barriers to those steps. If there is not concordance, this gap analysis opens an

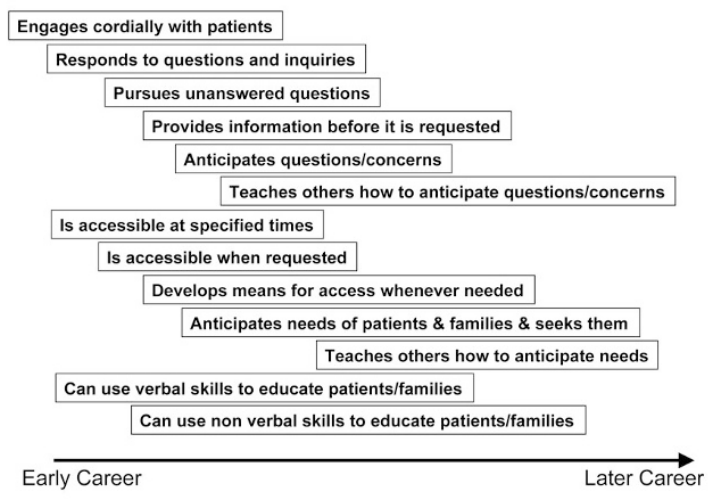

Figure 4. Interpersonal and communications skills: examples for development.

interesting and important discussion of why the perception is different, which can be punctuated by examples. If the student's self-perception differs from that of everyone else, this is an opportunity to explore why he/she is so misperceived.

- Use Flexibility in Residency-Time to Explore and Find Passion. At least 9 months, or up to 16 depending on how the electives are used, provide flexibility of $3 \mathrm{y}$. Use this time productively instead of filling voids in coverage. Maybe the thought that experiment should be conducted to see what the clinical service would look like if residents were not available for those 9 mo. Then reinsert them after considering what would advance their education. Perhaps, this would be time to have an extended and deep investment in chronically ill children with complete immersion and major responsibility - not to shape the workforce, but to inculcate the value of extended investment in patients-a quality we would like our personal physicians to have.

- Learn what practitioners do not know and use this to shape on-going education. When we are engaged in a Continuing Medical Education (CME) course, we traditionally teach, i.e. lecture, about a topic of our interest and we have little idea whether this fills a void in education; we only know it fills a void in our schedule. We can be far better informed about the educational needs for clinical practice if we harness the data we have at hand. As an example, we have created a Subspecialty Telephone Consultation Network for Primary Care Providers of Medicaid patients in Northern Texas; with some differences, this is analogous to what others have developed in North Carolina for subspecialty consultation or in Massachusetts (http://www.mcpap.com/ about.asp), specifically for pediatric psychiatric services. Our intention is certainly to shape care; reinforce the medical home; reduce unnecessary clinic visits, hospital transfers, or laboratory tests; reduce costs related to lost school for children and lost work for parents; and to prompt and arrange needed clinic consultation. However, it is also an opportunity to learn what primary care practitioners need to know, to reinforce what is understood, and to shape and reinforce new knowledge as medicine evolves. Indeed, from the nature and frequency of the questions, we have a terrific opportunity to discern what gaps exist as our residents enter 
primary care in a community. This is a database that we have rarely tapped. The skills and knowledge that are needed in practice vary based on demands for care and other resources available. What better way to identify those needs.

- Increase accountability for learning. This is a bilateral effort for learner and teacher, initiated by raising expectations. To the residents reading this, take mastery of your education: Do not ask "what to do." Consider the problem, propose an approach and rationale. Request affirmation or rationale for an alternative. Every patient interaction represents an opportunity to learn. For those of us who serve as teachers, we must resist the urge to give an answer. The more we say, the less is learned. Ask "why"... not "what." First critique the response, not the responder. Take time to get to foundation of knowledge and then help build on it. Engage those who are not participating. This concept is summarized by Fred Friendly who said, "My job is to make the agony of decision making so intense that you can only escape by thinking."

- Do Not Let Learners Ignore an Observation Just Because the Data Do Not Fit a Preconceived Notion. Throughout medical education, we constantly prime and reward students for rapid association and quick answers. We test recall of familiar elements rather than probe what cannot be reconciled. This is certainly the strategy we cultivate for some standardized tests. On rounds, students would rather remain silent and unseen than propose a potentially erroneous answer. We must teach them not to discard data. What does not fit often provides novel insight to a patient's problem. We should require reconciliation of all findings. We should also reassess the way we test and reward. Perhaps it is time to dust off the oral examinations; or better yet, we should spend more time interacting so that we can understand how our students and residents analyze a problem.

- Change the language and format of clinical discussions. We should ban shortcuts for discussion and analysis. We should be aware of reliance on heuristics, algorithms, and pattern recognition without justification by the learner for the reasoning. We should eliminate the differential diagnosis unless attached to a crisp rationale. The differential diagnosis that is an exhaustive laundry list rather than a rigorous assessment of findings is useless. We must require residents to explain their diagnostic reasoning for including or excluding a diagnosis or we are not fulfilling our role as teachers. When possible, eliminate acronyms and jargon; these often obfuscate rather than illuminate. Have you ever heard this type of presentation: This is a premature infant with history of PDA and IVH, now has BPD with increasing FOC, on with increasing CPAP, develops low BUN, and high $\mathrm{FENa}^{+}$, is now thought to have this condition. (Answer: What is SIADH.) Alright, I own up to my own limitations as an acronym challenged physician. Am I the only one with this disability? However, even for those of you facile with this lingo, it leaves many out of the conversation and others nodding as if they understand but are really lost. We often see residents nodding their heads as if they understand what is being said when they are simply too embarrassed to say they do not. I would argue that few things interfere more with comprehension or inquiry than jargon we use, which everyone is supposed to understand. These terms have a high risk of leaving the interested but perhaps reticent learner out of the conversation.

\section{Summary}

We as leaders cannot sit and complain about the change in culture, intrusion of regulations, generational differences between us and our students, and erosion of education. We can certainly write letters to others, but we should be writing to ourselves because we have the means to initiate change. This is our obligation and our mandate and I hope we have the energy, imagination, and perseverance.

\section{REFERENCES}

1. Gladwell M 2008 Outliers: The Story of Success. Little, Brown and Co, New York, pp 35-68

2. Flexner A 1910 Medical Education in the United States and Canada: A Report to the Carnegie Foundation for the Advancement of Teaching. Carnegie Foundation for the Advancement of Teaching, New York

3. Piele E 2002 Iconoclast: Abraham Flexner and a life in learning. BMJ 325:1248

4. Millis JS 1966 The Graduate Education of Physicians: The Report of the Citizens Commission on Graduate Medical Education. American Medical Association, Chicago. Available at: http://www.aafpfoundation.org/online/etc/medialib/found/ documents/programs/chfm/millisreport.Par.0001.File.dat/Millis_Report.pdf. Accessed March 16, 2011

5. American Academy of Pediatrics Task Force on Pediatric Education 1978 The Future of Pediatric Education: A Report by the Task Force on Pediatric Education. American Academy of Pediatrics, Evanston, Illinois

6. Task Force on the Future of Pediatric Education 2000 The future of pediatric education II. Organizing pediatric education to meet the needs of infants, children, adolescents, and young adults in the 21 st century. A collaborative project of the pediatric community. Pediatrics 105:157-212

7. Wise PH 2004 The transformation of child health in the United States. Health Aff (Millwood) 23:9-25

8. Lister G, Murdock-Vlautin TC, Friedman AL 2009 Report of colloquium I: the future of pediatric health care delivery and education-pondering imponderables to create an ideal residency in a world of critical uncertainties. Pediatrics 123:S12-S16

9. Rittel H, Webber M 1973 Dilemmas in a general theory of planning. Policy Sci 4:155-169 